\title{
Effect of Packaging Films on the Quality of Canola Oil under Photooxidation Conditions
}

\author{
Hao Sun, ${ }^{1,2}$ Li-xin Lu, ${ }^{1,2}$ Chang-feng Ge, ${ }^{3}$ and Ya-li Tang ${ }^{1,2}$ \\ ${ }^{1}$ Department of Packaging Engineering, Jiangnan University, Wuxi 214122, China \\ ${ }^{2}$ Jiangsu Key Laboratory of Advanced Food Manufacturing Equipment and Technology, Wuxi 214122, China \\ ${ }^{3}$ Rochester Institute of Technology, 78 Lomb Memorial Drive, Rochester, NY 14623, USA \\ Correspondence should be addressed to Li-xin Lu; lulx@jiangnan.edu.cn
}

Received 10 September 2014; Revised 20 February 2015; Accepted 20 February 2015

Academic Editor: Gisele Mophou

Copyright (C) 2015 Hao Sun et al. This is an open access article distributed under the Creative Commons Attribution License, which permits unrestricted use, distribution, and reproduction in any medium, provided the original work is properly cited.

\begin{abstract}
The objective of this study was to evaluate the influence of packaging films on the quality of canola oil which contains high concentration of fat under photooxidation condition and get the oxidation kinetics based on measuring the oxidation intensities including peroxide value, hexanal, and photosensitizer (chlorophyll). The canola oil was packaged by PET/CPP; KPET/PE was used for experiments. The change of light and oxygen transmission rate (OTR) of PET/CPP which was considered as the typical fatty foods packaging film under different light intensities was also tested. The results show that the peroxide value increased rapidly under light conditions and fitted the zero order kinetics; also the oxygen transmission rate had great impact on it; hexanal fitted the zero order kinetic in oil whose package of low OTR generated a lot; however package in high OTR films changed very slowly that might be dependent on the performance of hexanal through plastic films. The degradation of chlorophyll fitted the first order kinetic and decreased quickly under light but was almost independent of OTR of transparent packaging material. Light reduced the oxygen barrier properties of the films, which should be considered as the photooxidation condition (and the photooxidation condition thus should be considered).
\end{abstract}

\section{Introduction}

Many studies have shown that the types of packaging materials (plastic, glass), storage conditions (temperature, light), and storage time have a significant impact on the quality of fatty foods during the storage. In order to assess the shelf life of packaged fatty foods, choosing different storage conditions and packaging materials to be tested are particularly important [1].

During the storage, fatty foods deteriorate easily due to bad sealing of the packaging containers or packaging materials with high oxygen transmission rate (OTR) [2] which cause food oxygen. The oxygen concentration has a great influence upon the oxidation. In another words, the rate of oxidation is also affected by the concentration of dissolved oxygen and OTR [1]. The rate increased with oxygen partial pressure when it has a low value, while there is no great influence on the lipid oxidation when it up to a certain value [3]. It was noted that the rates may be greatly different when packed by materials with large difference of OTR. However, the difference is not obvious in materials with low OTR. The peroxide value and the rate of hexanal which is a secondary product of oil oxidation of fatty foods package in different materials increased with OTR both in light and in dark conditions [4]. In the study of evaluation of the shelf life of olive oil in glass, PET, and PVC bottles under light, the differences of OTR of the materials made a little effect on the lipid oxidation taken hexanal as the oxidation index. As oxygen, hexanal could be sorbed by the polymeric packaging materials [5]. In addition, the light transmission of packaging materials also influences the oxidation [6]. In summary, the quality of fatty foods with plastic films of different properties turns to be quite different in light condition.

The courses of fat food oxidation are mainly autoxidation and photooxidation, and the rate of photooxidation is rather higher than autooxidation [3]. Under light, photosensitivity in food absorbs energy and then turns to be activated. During this process, reactant in oil is activated and turns to be free radical group (type I photosensitizer), or triplet oxygen $\left({ }^{3} \mathrm{O}_{2}\right)$ turns to be singlet oxygen $\left({ }^{1} \mathrm{O}_{2}\right)$ which has powerful reactivity 
TABLE 1: Fatty acid composition of canola oil.

\begin{tabular}{lcc}
\hline & \multicolumn{2}{c}{ Fatty acid composition of canola oil } \\
\hline Oleic acid & Linoleic acid & Linolenic acid \\
$(\mathrm{C} 18: 1)$ & $(\mathrm{C} 18: 2)$ & $(\mathrm{C} 18: 3)$ \\
$56.99 \%$ & $19.46 \%$ & $8.0 \%$ \\
\hline
\end{tabular}

${ }^{*}$ Provided by the state key laboratory of food science and technology.

(type II photosensitizer). Due to its high energy, singlet oxygen can react directly with unsaturated fatty acids and generate hydrogen peroxide $[7,8]$. And hydrogen peroxide degrades by the promoting of light and then generates large amounts of volatiles $[1,2]$. The degradation of chlorophyll which is largely found in edible oils (virgin olive oil, canola oil, etc.) [9] fits the first-order kinetic $[10,11]$, while the content of hexanal is one of the most commonly used oxidation index and satisfies zero-order kinetics [12-14].

Moreover, light not only undermines the quality of foods but also affects the performance of packaging materials, especially plastics, resulting in light aging, oxidative degradation, embrittlement, and the performance degradation. In order to prevent the aging, the antioxidants are added in the generation process of the plastic films [15].

The aims of this study are to (1) evaluate the influence of packaging films on the quality of packed canola oil; (2) obtain the oxidation kinetics based on measuring the oxidation intensities including peroxide value, hexanal, and photosensitizer (chlorophyll).

\section{Materials and Methods}

\subsection{Materials and Samples}

2.1.1. The Fatty Foods. Commercial canola oil (Jiangsu Golden Sun Oil Co., Ltd.) was purchased from a local supermarket. Fatty acid composition of canola oil was shown in Table 1.

2.1.2. Films with Different OTR. The films were with different gradient of OTR, including CPP25, CPP30, PET15/CPP20, and KPET15/PE50, provided by Wuxi Guotai Color Printing Co., Ltd., for the packaging of fatty foods, especially edible oil; the film package was asked for good oil resistance and oxygen-resistance. And for light experiments, unprinted transparent were also required. The OTR of packaging film for oil is not greater than $12 \mathrm{~cm}^{3} / \mathrm{m}^{2} \cdot \mathrm{d}$ and the film commonly used is NY15/PE40 [17]. This paper discussed the change of oil quality packaged by different OTR films in the light. The properties of films were shown in Table 2.

2.1.3. Samples Preparation. Cut all films into $180 \times 90 \mathrm{~mm}$ for madding pockets. The oil that can be divided by $10 \mathrm{~mL}$ was poured into the pockets, and the pockets were sealed after excluding all air. The heat sealing temperature is $150^{\circ} \mathrm{C}$; finally get the sample filled with oil whose inside dimension is $60 \times$ $50 \mathrm{~mm}$.

2.2. Experimental Condition. The test of influence of packaging films on photooxidation was finished in a PQX-330D multisection programmable climate-regulating chamber. Film packaged oil samples were stored for 3 weeks at $23^{\circ} \mathrm{C}, 50 \% \mathrm{RH}$ under the light condition with 1000 lux measured by TES-1330A digital illumination meter (Taishi electronic, Taiwan). Samples were placed in cardboards, and the cardboards were placed parallel with the lamp, which ensured that the samples received the even light in single side.

The light accelerated test of PET/CPP was also finished in the PQX-330D multisection programmable climateregulating chamber. PET/CPP was placed as the oil samples and stored at $23^{\circ} \mathrm{C}, 50 \% \mathrm{RH}$ under the light condition with 1000, 3000, and 5000 lux, respectively, for 4 weeks. The light and oxygen transmission rate were tested and compared with the film without light.

\subsection{Analytical Determinations}

2.3.1. Peroxide Value. Peroxide value was measured according to GB/T 5009.37-2003 method for analysis of hygienic standard of edible oil methods [18], using colorimeter.

2.3.2. Chlorophyll. Chlorophyll was measured by SN/T 0801.21-2001 method for determination of chlorophyll of import and export animal and vegetable fats [19].

2.3.3. Headspace Volatile. Shimadzu gas chromatograph GC2010: using headspace injector, valve box temperature was set to $100^{\circ} \mathrm{C}$; column: micropolar capillary column RTX-5 was used whose length is $30 \mathrm{~m}$; temperature program: initial column temperature was $40^{\circ} \mathrm{C}$ and was kept for 5 minutes and then increased to $180^{\circ} \mathrm{C}$ with the rate of $10^{\circ} \mathrm{C} / \mathrm{min}$ and kept for 5 minutes; carrier gas was high purity nitrogen; the linear flow rate was $0.03 \mathrm{~cm}^{3} / \mathrm{s}$, splitless; inlet temperature was set to $240^{\circ} \mathrm{C}$; FID detector temperature was set to $260^{\circ} \mathrm{C}$.

2.3.4. OTR. OTR was measured by GB/T1038-2000 plastics film and sheeting determination of gas transmission differential pressure method [14].

2.3.5. Light Transmission Rate. Obtaining spectral scans by UV-2802 spectrophotometer.

\section{Results and Discussion}

3.1. The Influence Of Packaging Films on the Photooxidation. The changes of different oxidation indexes of canola oil packaged with different films under dark and light were shown in Figure 1. The results showed that the quality of canola oil had no significant change in the dark. The peroxide value increased gradually while the changes of chlorophyll and hexanal were hardly tested. In lighting condition, the peroxide value rose sharply and linearly, and its rate grew with the increase of OTR of packaging films. Chlorophyll decreased significantly in the whole process, and the degradation rates of oil packaged in different films were basically the same, having a little relationship with OTR. The hexanal in CPP25 changed little. The rate of hexanal in films is 
TABLE 2: The properties of packaging materials.

\begin{tabular}{|c|c|c|c|}
\hline Film & Thickness/ $\mu \mathrm{m}$ & Average visible light transmittance ${ }^{* *}$ & $\begin{array}{l}\text { Oxygen permeability } \\
\text { rate }^{* * *} / \mathrm{cm}^{3} /\left(\mathrm{m}^{2} \cdot \mathrm{d}\right)\end{array}$ \\
\hline PET15/CPP20 & $35.2 \pm 2.4$ & $87.1 \pm 4.0 \%$ & $69.2 \pm 5.6$ \\
\hline KPET15/PE50 & $64.8 \pm 3.1$ & $80.4 \pm 3.3 \%$ & $9.0 \pm 0.7$ \\
\hline СРP25 & $24.7 \pm 2.0$ & $89.7 \pm 3.9 \%$ & $1145.4 \pm 75.2$ \\
\hline СРP30 & $30.1 \pm 2.2$ & $86.9 \pm 3.2 \%$ & $807.5 \pm 50.5$ \\
\hline
\end{tabular}

** Use UV-2802 spectrophotometer to obtain spectral scans.

*** According to GB/T 1038-2000 [16], tested by China National Light Industry Package Quality Supervising \& Testing Center.

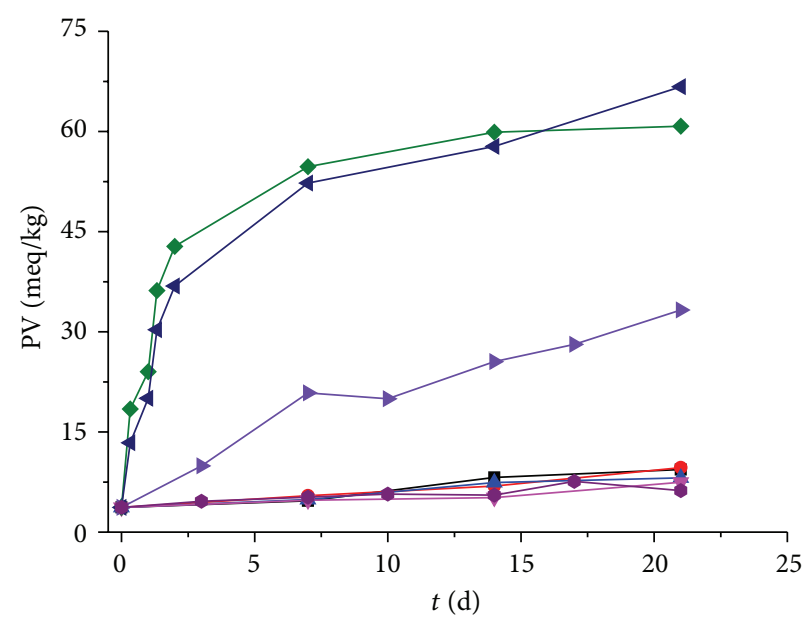

(a) PV

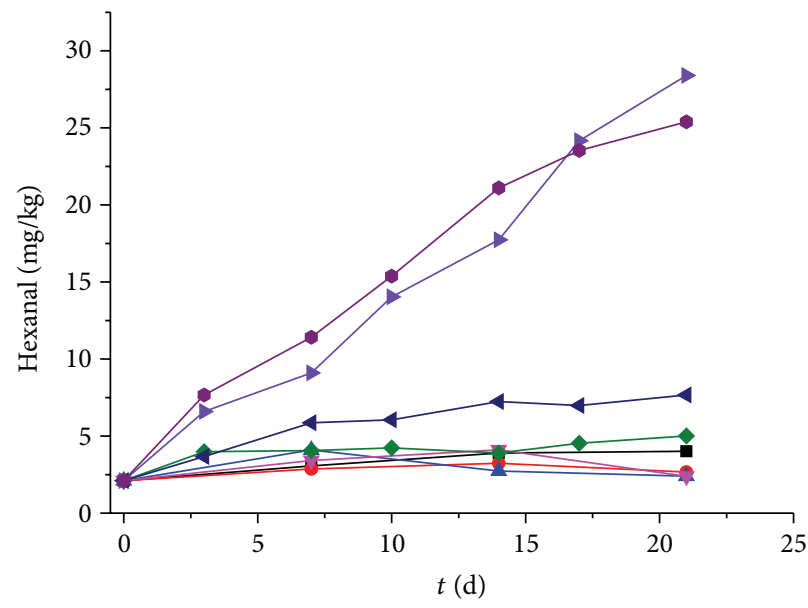

(b) Hexanal

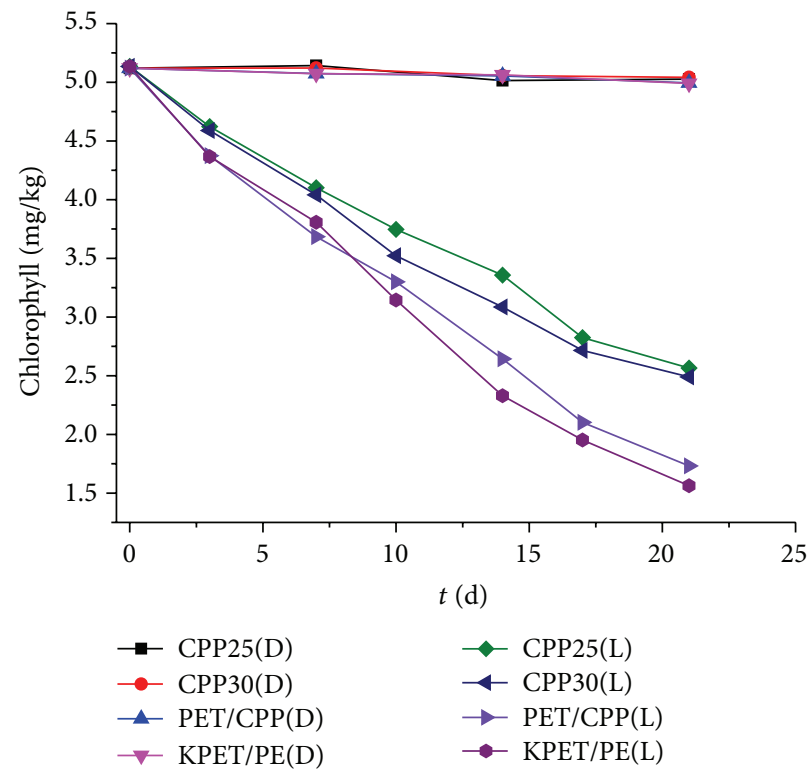

(c) Chlorophyll

FIGURE 1: The changes of oxidation indexes of canola oil packaged with different films under dark and light condition.

$\mathrm{CPP} 25<\mathrm{CPP} 30<\mathrm{PET} / \mathrm{CPP} \approx \mathrm{KPET} / \mathrm{PE}$. A large amount of hexanal was generated quickly, which is slightly larger than the former, unrelated with the OTR of the two.

Thus, we can get the following conclusions.

(1) Peroxide value (PV), as a common oxidation indicator in lots of research on lipid oxidation, is used for oxidation evaluation, light grease, The increase of PV is faster than in the dark, and fitted a zero order kinetic. The OTR of packaging films had a great influence on the oxidation rate. It had a great advantage on commenting on the oxidation of fatty foods packaged by films with different OTR. Also it changed discriminatively under different light intensities when 
the oil was packed in sealed glass bottles with head space $[20,21]$. To know whether it is suitable for the fatty foods packaged by films with low OTR tested under different light intensities, further validation is needed.

(2) Hexanal is the major secondary oxidation product in most of fatty foods and the volatile aldehydes are not identical to photooxidation or autoxidation in high or low oxygen environment $[8,22]$. The formation of hexanal was not detected in the dark, which may be related to the degree of oxidation and oxidation products. It stayed at a low level under light in CPP with high OTR. To validate the performance of hexanal transmission performance of the films, two samples of oil were placed in sealed and open glass bottles with large headspace and were stored under the same light conditions and the test results were shown in Table 2 . The content of hexanal in the sealed bottle was larger than the open one which could be considered such that the films with high OTR had high hexanal transmission performance and hexanal volatized quickly during the storages. Combining with the formation of hexanal and hexanal transmission rate could predict the shelf life of such fatty foods [5, 23]. However it was also proposed that hexanal analysis was more sensitive than PV measurement for evaluating lipid oxidation [14]. According to test, taking hexanal as the oxidation indicator was more suitable for oil package in low OTR films and the hexanal formation in such packaging environment fitted a zero order kinetic (Table 3).

(3) Chlorophyll as a photosensitizer degraded extremely slowly in the dark, while the light contributed greatly to the degradation. It is why PV increased rapidly in the light. Chlorophyll absorbed light energy and at the meantime degraded under light condition. The absorber energy turned triplet oxygen $\left({ }^{3} \mathrm{O}_{2}\right)$ to singlet oxygen $\left({ }^{1} \mathrm{O}_{2}\right)$ which has powerful reactivity and combined with unsaturated fatty acids to generate hydrogen peroxide $[1,3]$. As Figure 1, the degradation of chlorophyll followed a first order kinetic. The OTR of films made no significant different effects on the degradation. Studies have shown that the degradation of chlorophyll related with oxygen concentration [24]. In this experiment, the degradation of chlorophyll was independent of oxygen. Chlorophyll in the high OTR film degraded slightly slower than in low OTR films which might be due to the lower stiffness of CPP. The oil gathered at the bottom of the bag at the force of gravity which caused less exposure to light compared to oil packaged in PET/CPP and $\mathrm{KPET} / \mathrm{PE}$. So to a certain degree the degradation of chlorophyll could reflect the oxidation degree of canola oil in the specific environment. Froydis Bjerke has already taken the change of photosensitizer to evaluate the photooxidation of fatty foods [25].
TABLE 3: The difference of oxidation index in open and closed containers under light.

\begin{tabular}{lccc}
\hline & PV/meq $/ \mathrm{kg}$ & Hexanal $/ \mathrm{mg} / \mathrm{kg}$ & Chlorophyll $/ \mathrm{mg} / \mathrm{kg}$ \\
\hline Sealed bottle & $47.9 \pm 3.2$ & $21.5 \pm 1.6$ & $1.2 \pm 0.07$ \\
Open bottle & $53.7 \pm 3.9$ & $9.8 \pm 0.8$ & $1.1 \pm 0.08$ \\
\hline
\end{tabular}

TABLE 4: The kinetics equation of canola oil packaged with different films under light.

(a) PV

\begin{tabular}{lcc}
\hline Films & Regression equation & $R$-square \\
\hline CPP25 & $3.694+21.32 t$ & 0.904 \\
CPP30 & $3.694+17.63 t$ & 0.956 \\
PET/CPP & $3.694+1.516 t$ & 0.915 \\
KPET/PE & $3.694+0.165 t$ & 0.695 \\
\hline
\end{tabular}

(b) Hexanal

\begin{tabular}{lcc}
\hline Films & Regression equation & $R$-square \\
\hline CPP25 & $2.104+0.155 t$ & 0.311 \\
CPP30 & $2.104+0.316 t$ & 0.788 \\
PET/CPP & $2.104+1.225 t$ & 0.986 \\
KPET/PE & $2.104+1.231 t$ & 0.967 \\
\hline
\end{tabular}

(c) Chlorophyll

\begin{tabular}{lcc}
\hline Films & Regression equation & $R$-square \\
\hline CPP25 & $5.12 \exp (-0.0325 t)$ & 0.994 \\
CPP30 & $5.12 \exp (-0.0359 t)$ & 0.996 \\
PET/CPP & $5.12 \exp (-0.0490 t)$ & 0.993 \\
KPET/PE & $5.12 \exp (-0.0533 t)$ & 0.987 \\
\hline
\end{tabular}

3.2. The Kinetics of the Oxidation Index of the Packed Oil under Light Conditions. This research showed that peroxide value and hexanal of vegetable oil fit zero order kinetics. The degradation of chlorophyll fits first order kinetics:

$$
\begin{gathered}
\mathrm{PV}=\mathrm{PV}_{0}+k_{p} t, \\
C_{\text {hexanal }}=C_{\text {hexanal } 0}+k_{h} t, \\
C_{\text {chlorophyll }}=C_{\text {chlorophyll }_{0}} \exp \left(-k_{c} t\right),
\end{gathered}
$$

where $\mathrm{PV}$ is peroxide value, meq/ $\mathrm{kg} ; C_{\text {hexanal }}$ is the concentration of hexanal, $\mathrm{mg} / \mathrm{kg} ; C_{\text {chlorophyll }}$ is the concentration of chlorophyll, $\mathrm{mg} / \mathrm{kg} ; k_{p}$ is the formation rate of peroxide value, $\mathrm{meq} / \mathrm{kg} \cdot \mathrm{d} ; k_{h}$ is the formation rate of hexanal, $\mathrm{mg} / \mathrm{kg} \cdot \mathrm{d} ; k_{c}$ is the degradation rate of chlorophyll, $\mathrm{mg} / \mathrm{kg} \cdot \mathrm{d} ; t$ is time, $\mathrm{d}$.

According to the experimental data, the fitting equation was shown in Table 4.

3.3. The Influence of Light Intensities on the Properties of the Typical Packaging Film. Light accelerated test was studied for PET15/CPP20 as the typical packaging film. The light transmission rate changed little under different light intensities, while the changes of OTR after exposing to 1000, 3000, and 5000 lux light conditions for four weeks were raised by $5.7,14.2$, and $20.3 \%$, respectively, as shown in Table 5. The 
TABLE 5: The change of ORT under different light intensities of PET15/CPP20.

\begin{tabular}{lccc}
\hline $\begin{array}{l}\text { Light } \\
\text { intensity/lux }\end{array}$ & $\begin{array}{c}\text { Initial } \\
\mathrm{OTR} / \mathrm{cm}^{3} / \mathrm{m}^{2} \cdot \mathrm{d}\end{array}$ & $\begin{array}{c}\text { Final } \\
\mathrm{OTR} / \mathrm{cm}^{3} / \mathrm{m}^{2} \cdot \mathrm{d}\end{array}$ & $\begin{array}{c}\text { Change } \\
\text { range/\% }\end{array}$ \\
\hline 1000 & $69.2 \pm 5.6$ & $73.1 \pm 6.4$ & 5.7 \\
3000 & $69.2 \pm 5.6$ & $79.0 \pm 6.6$ & 14.2 \\
5000 & $69.2 \pm 5.6$ & $83.2 \pm 7.0$ & 20.3 \\
\hline
\end{tabular}

influence of OTR on the lipid oxidation above showed that the rate of PV rose with OTR and the rates of hexanal packaged in low OTR films had less difference under light which might relate with the hexanal transmission rate of films. However due to the restrictions of experimental conditions, the hexanal performance of material could not be determined. The changes of properties of packaging films during the light accelerated test should be paid some attention. And combined with the light accelerated test of the influence of light intensities on the lipid oxidation later, the influence degree of the change of film properties during the accelerated test on lipid oxidation could be further determined; then the suitable light intensities and exposure time of the light accelerated test can be made.

\section{Conclusions}

PV increased rapidly under light especially in high OTR films. It could well evaluate the lipid oxidation of fatty foods packaged in films with different OTR. But hexanal was formed a lot in films with excellent barrier which related to light, oxygen, and hexanal transmission rate of the films. We noted that PV of canola oil packaged in low OTR film such as KPET/PE changed a little both in dark or in light; meanwhile hexanal rose quickly in light condition, which gave the better explanation that light promotes the degradation of hydrogen peroxide. So taking hexanal as the oxidation index of fatty foods package in such films is more appropriate. In addition, the degradation of chlorophyll could reflect the oxidation degree in some specific environment. Light reduced the oxygen barrier properties of films, which was not considered in this study. We will consider the problems in the successive research.

\section{Conflict of Interests}

The authors declare that there is no conflict of interests regarding the publication of this paper.

\section{Acknowledgments}

This work was supported by the Achievements Industrialization Prospective Research Project of Jiangsu Province Grant no. BY2013025-26 and by the Fundamental Research Funds for the Central Universities (JUSRP51403A).

\section{References}

[1] A. Kanavouras, P. Hernandez-Munoz, and F. A. Coutelieris, "Packaging of olive oil: quality issues and shelf life predictions," Food Reviews International, vol. 22, no. 4, pp. 381-404, 2006.
[2] D.-T. Pan, "The reasons of lipid oxidation and the measures for protection," Tianjin Grain and Oil Technology, vol. 2, pp. 6-7, 1997.

[3] F. Feng-qin and Y. Li-yang, Food Chemistry, Chemical Industry Press, Beijing, China, 2005.

[4] S. F. Mexis and M. G. Kontominas, "Effect of oxygen absorber, nitrogen flushing, packaging material oxygen transmission rate and storage conditions on quality retention of raw whole unpeeled almond kernels (Prunus dulcis)," LWT_Food Science and Technology, vol. 43, no. 1, pp. 1-11, 2010.

[5] A. Kanavouras and F. A. Coutelieris, "Shelf-life predictions for packaged olive oil based on simulations," Food Chemistry, vol. 96, no. 1, pp. 48-55, 2006.

[6] L.-X. Lu and F. Xu, "Effect of light-barrier property of packaging film on the photo-oxidation and shelf life of cookies based on accelerated tests," Packaging Technology and Science, vol. 22, no. 2, pp. 107-113, 2009.

[7] H. H. Chang, Quantitative Changes of Volatile Compound in Soybean and Algal Oil and Effects of Antioxidants on the Oxidative tability of Algal Oil under Light Storage, The Ohio State University, Columbus, Ohio, USA, 2011.

[8] X.-Z. Zhao, Food Chemistry, Chemical Industry Press, Beijing, China, 2005.

[9] E. Psomiadou and M. Tsimidou, "Stability of virgin olive oil. 2. Photo-oxidation studies," Journal of Agricultural and Food Chemistry, vol. 50, no. 4, pp. 722-727, 2002.

[10] D. F. Olds, Use of a xenon arc lamp exposure system for accelerated photostability testing of food model systems [M.S. thesis], San Jose State University, San Jose, Calif, USA, 1994.

[11] L. Manzocco, G. Kravina, S. Calligaris, and M. C. Nicoli, "Shelf life modeling of photosensitive food: the case of colored beverages," Journal of Agricultural and Food Chemistry, vol. 56, no. 13, pp. 5158-5164, 2008.

[12] S. Calligaris, S. Sovrano, L. Manzocco, and M. C. Nicoli, "Influence of crystallization on the oxidative stability of extra virgin olive oil," Journal of Agricultural and Food Chemistry, vol. 54, no. 2, pp. 529-535, 2006.

[13] S. Calligaris, L. Manzocco, and M. C. Nicoli, "Modelling the temperature dependence of oxidation rate in water-in-oil emulsions stored at sub-zero temperatures," Food Chemistry, vol. 101, no. 3, pp. 1019-1024, 2007.

[14] T.-S. Yang, Y.-H. Chu, and T.-T. Liu, "Effects of storage conditions on oxidative stability of soybean oil," Journal of the Science of Food and Agriculture, vol. 85, no. 9, pp. 1587-1595, 2005.

[15] S.-N. Pan, Packaging Technology, Printing Industry Press, Beijing, China, 1998.

[16] Standards Press of China, "Plastics film and sheeting determination of gas transmission differential pressure method," Tech. Rep. GB/T 1038-2000, Standards Press of China, Beijing, China, 2000.

[17] C. Tao, "Packaging materials of noodle soup," Food Science and Technology, vol. 2, pp. 76-77, 1998.

[18] GB/T 5009.37-2003, Method for Analysis of Hygienic Standard of Ebile Oil Methods, Standards Press of China, Beijing, China, 2003.

[19] Standards Press of China, "Method for the determination of chlorophyll of import and export animal and vegetable fats," Tech. Rep. SN/T 0801.21-2001, Standards Press of China, Beijing, China, 2001.

[20] L. Manzocco, A. Panozzo, and S. Calligaris, "Accelerated shelf life testing (ASLT) of oils by light and temperature exploitation," 
Journal of the American Oil Chemists' Society, vol. 89, no. 4, pp. 577-583, 2012.

[21] A. Kanavouras, P. Hernandez-Münoz, and F. A. Coutelieris, "Shelf life predictions for packaged olive oil using flavor compounds as markers," European Food Research and Technology, vol. 219, no. 2, pp. 190-198, 2004.

[22] B. Sionek, K. Krygier, K. Ukalski, J. Ukalska, and R. Amarowicz, "The influence of nitrogen and carbon dioxide on the oxidative stability of fully refined rapeseed oil," European Journal of Lipid Science and Technology, vol. 115, no. 12, pp. 1426-1433, 2013.

[23] F. A. Coutelieris and A. Kanavouras, "Experimental and theoretical investigation of packaged olive oil: development of a quality indicator based on mathematical predictions," Journal of Food Engineering, vol. 73, no. 1, pp. 85-92, 2006.

[24] C.-D. Huang and X.-S. Hu, "The kinetics research of chlorophyll degradation of post-harvest fruits and vegetables under light," Journal of Agricultural Engineering, vol. 24, no. 10, pp. 233-239, 2008.

[25] F. Bjerke, H. Larsen, and S. G. Tellefsen, "Analysing multivariate data from designed experiments: a case study of photooxidation in sour cream," Quality and Reliability Engineering International, vol. 23, no. 6, pp. 679-688, 2007. 


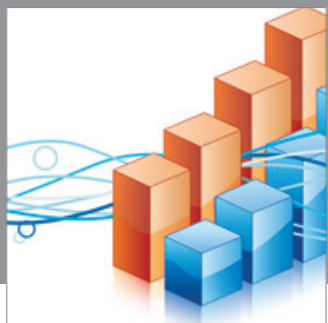

Advances in

Operations Research

mansans

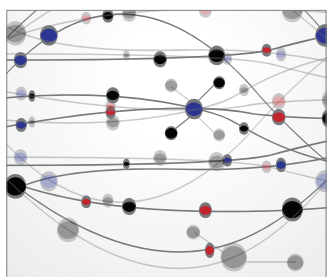

The Scientific World Journal
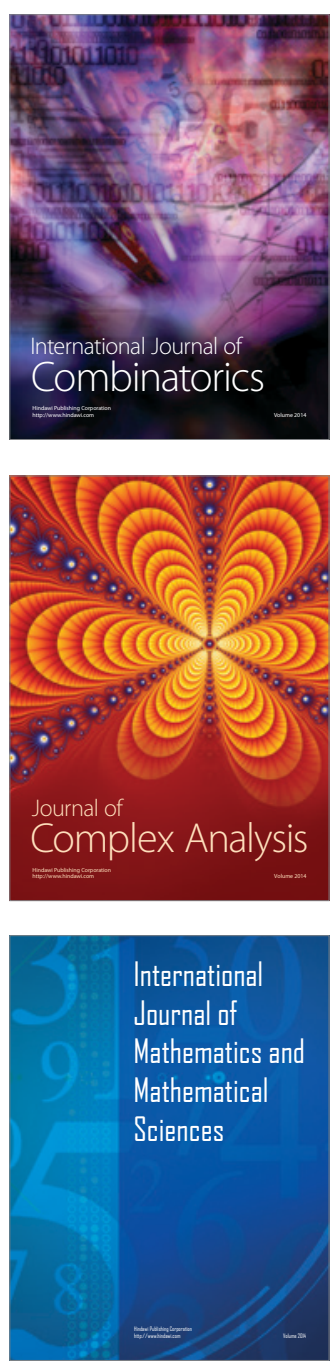
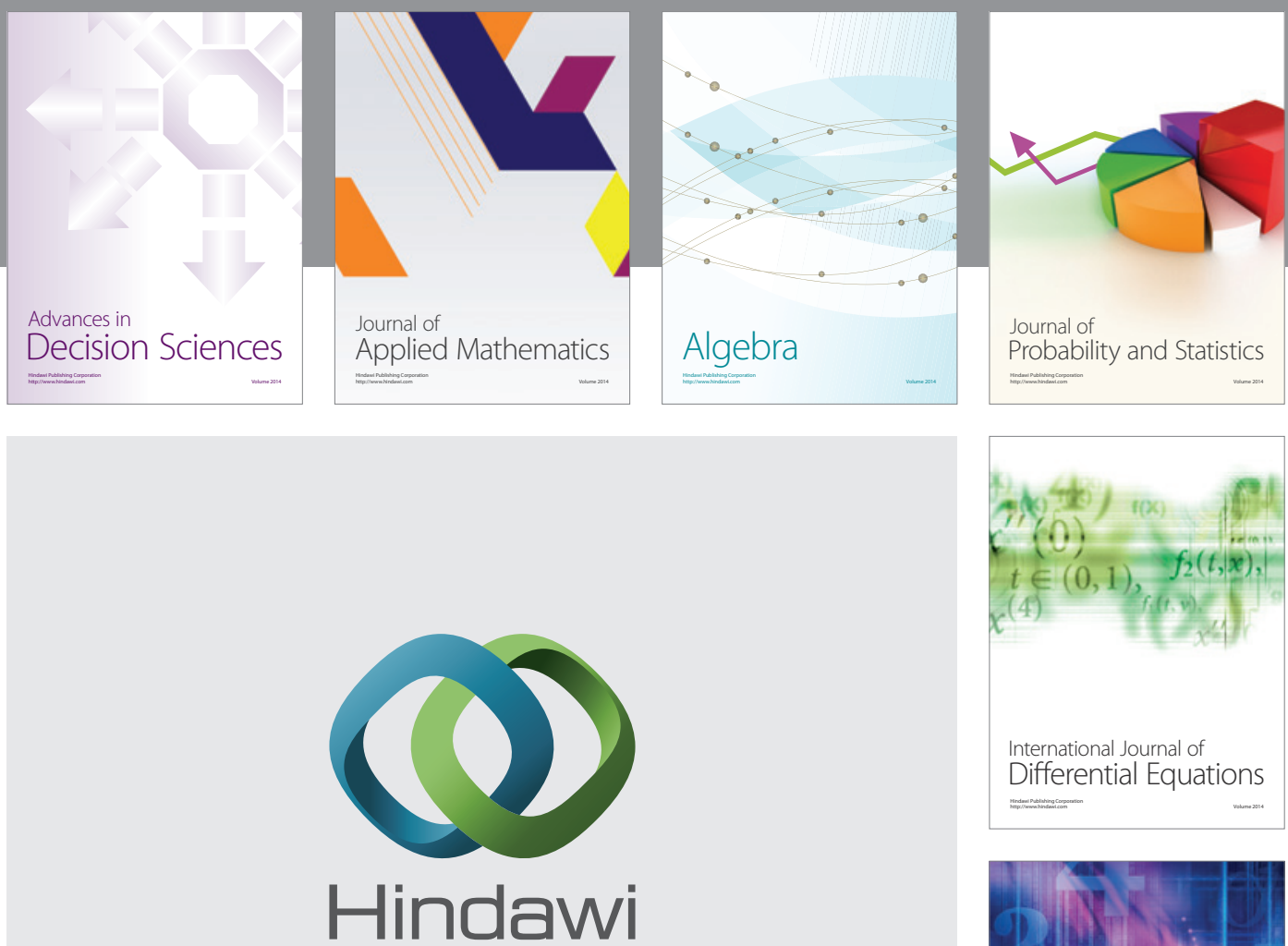

Submit your manuscripts at http://www.hindawi.com
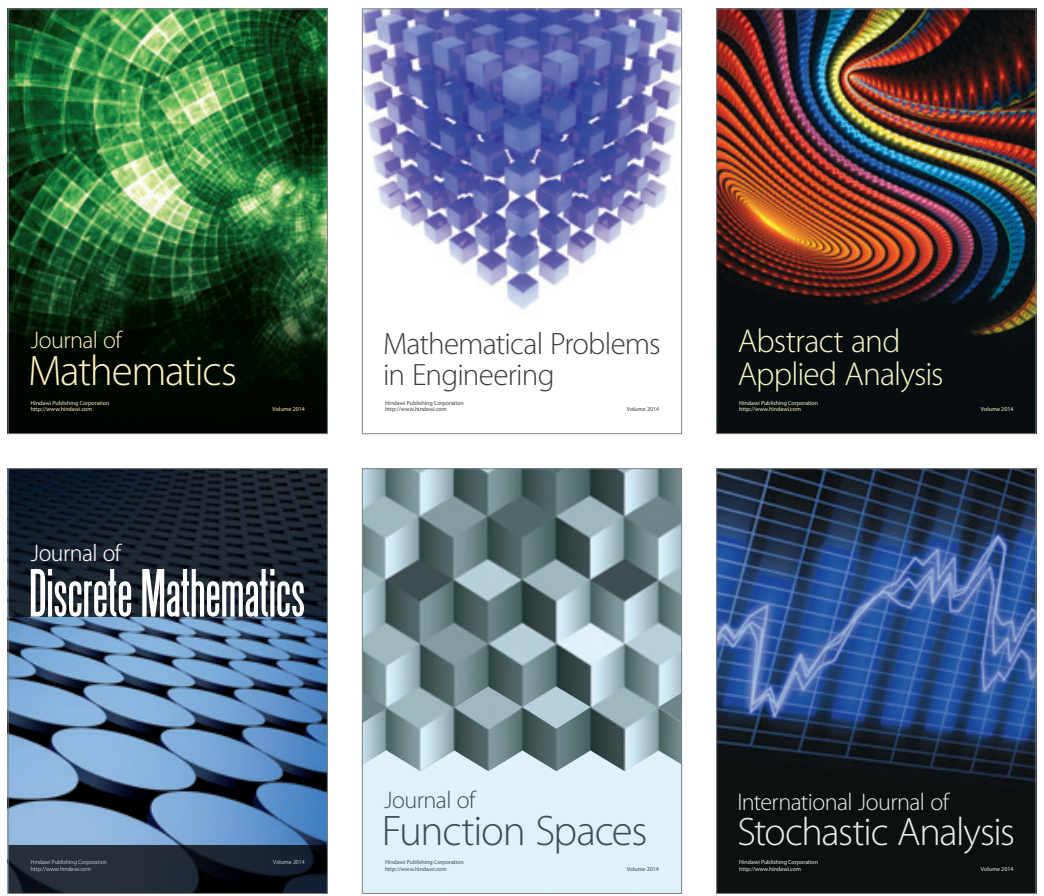

Journal of

Function Spaces

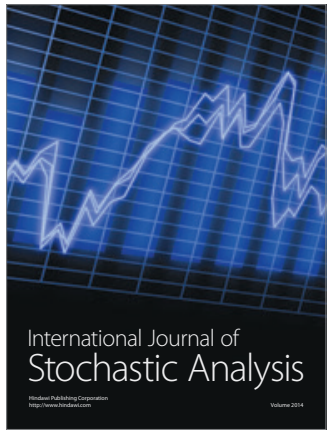

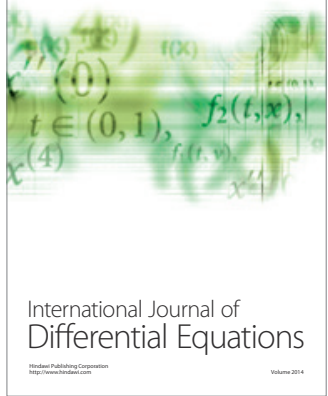
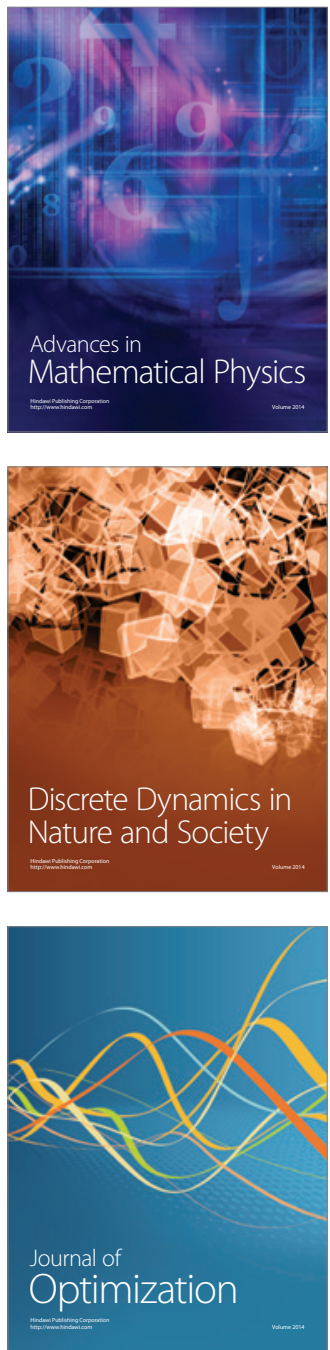